\title{
VIVENCIANDO O PARTO HUMANIZADO: UM ESTUDO FENOMENOLÓGICO SOB A ÓTICA DE ADOLESCENTES*
}

\author{
LIVING THE HUMANIZED DELIVERY: A PHENOMENOLOGICAL STUDY FROM \\ THE POINT OF VIEW OF ADOLESCENTS
}

\section{VIVENCIANDO EL PARTO HUMANIZADO: UN STUDIO FENOMENOLÓGICO BAJO LA OPTICA DE ADOLESCENTES}

Zuleyce Maria Lessa Pacheco de Oliveira** Anézia Moreira Faria Madeira***

Oliveira ZMLP, Madeira AMF. Vivenciando o parto humanizado: um estudo fenomenológico sob a ótica de adolescentes. Rev Esc Enferm USP 2002; 36(2): 133-40.

\begin{abstract}
RESUMO
Este estudo teve por objetivo compreender o que significa para as adolescentes passarem pelo parto dito humanizado. Para isso, utilizei a fenomenologia como trajetória de pesquisa, para chegar a essência do fenômeno. Participaram do estudo oito adolescentes que foram atendidas no Hospital Sofia Feldman, instituição filantrópica, sem fins lucrativos - Belo Horizonte/MG. Para a coleta de dados utilizei observação de campo e entrevista aberta. O estudo possibilitou apreender três categorias de análise: Préparto/Parto: o corpo sendo controlado; Pré-parto/Parto: misto de dor e de prazer; Parto Humanizado: a assistência esperada e desejada.
\end{abstract}

PALAVRAS-CHAVE: Enfermagem materno-infantil. Adolescente. Humanização do parto.

\begin{abstract}
The purpose of this study was to comprehend the meaning of the humanized childbirth experience for teenage parturients. Phenomenology was adopted as the way to achieve the essence of the phenomenon. Eight teenagers who were assisted at the Sofia Feldman Hospital - a philantropic and non-profit-making institution-Belo Horizonte/MG - Brazil - have taken part of this study. Field work and open interview were the proceedures used for data collection. The study made it possible to seize three categories of analysis: Prechildbirth/Chilbirth - the body is being controlled. Prechildbirth/ Chilbirth - a combination of pain and pleasure; Humanized Childbirth - expected and desired care.
\end{abstract}

KEYWORDS: Maternal-child nursing. Adolescence. Humanized childbirth.

\section{RESUMEN}

Este estudio tuvo como objetivo compreender lo que significa para las adolescentes el hecho de pasar por un parto dicho humanizado. Para esto, utilizé la fenomenologia como trayectoria de investigación, para llegar a la esencia del fenómeno. Participaron del estudio adolescentes que fueron atendidos en el Hospital Sofia Feldman, instituición filantrópica, sin fines de lucro - Belo Horizonte/MG. Para la colecta de datos utilizé observación de campo y entrevista abierta. El estudio posibilitó aprender tres categorias de análisis: Pre-parto/Parto: el cuerpo siendo controlado; Pre-parto/Parto: mixto de dolor y de placer; Parto Humanizado: la asistencia deseada y esperada.

PALABRAS-CLAVE: Enfermería materno-infantil. Adolescencia. Humanization del parto.

\footnotetext{
Vivenciando o parto humanizado - um estudo compreensivo fenomenológico sob a ótica de adolescentes. Dissertação apresentada ao Curso de Mestrado em Enfermagem da EEUFMG - 2001.

** Enfermeira, Mestre em Enfermagem, Prof Assistente da INESP/UEMG, Campus de Divinópolis/MG.

*** Enfermeira, Doutora em Enfermagem, Prof Adjunto da EEUFMG - anezia@enf.ufmg.br
} 


\section{INTRODUÇÃO}

Antes mesmo de iniciar a vida profissional já me sentia incomodada ao ver situações constrangedoras nas quais as adolescentes passavam durante $o$ processo de parto. Elas ficavam, às vezes, em completo isolamento físico, social, e emocional, no momento em que iam ter seus filhos. Acredito que essa situação, conforme minha ótica de enfermeira obstetra, provocava medo, insegurança, solidão. Assim, passei a questionar, como seria para as adolescentes a vivência do parto com essas características? O que significa para elas passar por essa experiência quando ainda se é jovem? O parto demarcaria nitidamente a passagem para o mundo adulto? $\mathrm{O}$ parto humanizado seria o mais indicado para elas? Foram estas as inquietações que impulsionaram-me para o caminhar investigativo e a ingressar em hospitais direcionados para a humanização do parto.

Ingressei no Hospital Sofia Feldman, na cidade de Belo Horizonte-MG, uma instituição filantrópica, especializada na assistência à mulher, à criança e à adolescente, onde a humanização da assistência aos usuários vem sendo implantada como filosofia de trabalho desde sua inauguração, por meio de estratégias, tais como: alojamento conjunto, incentivo ao aleitamento materno ainda em sala de parto, presença de familiares ou acompanhante nas salas de pré-parto e parto e resgate do caráter natural e fisiológico do nascimento, no qual a mulher atua de forma ativa no processo, com o mínimo de procedimentos intervencionistas. ${ }^{(1)}$

Diante dessa proposta, dita humanizada, comecei a refletir e questionar se realmente essa assistência ao parto, adotada atualmente como filosofia em várias instituições que visam a melhoria do atendimento à gestante no ciclo gravídicopuerperal, estaria atendendo às expectativas das mulheres adolescentes. As atividades desenvolvidas nesses locais são suficientes para caracterizar o parto como humanizado? Ao vivenciar as experiências, no decorrer do trabalho de parto e no parto, conseguiriam as adolescentes descrever essa assistência como humanizada? Considero que só aqueles que vivenciam tal experiência poderão falar melhor sobre ela e, dessa forma, desvelar os aspectos essenciais.

O parto foi institucionalizado mais expressivamente no século $\mathrm{xx}$, após a Segunda Guerra Mundial, quando os médicos adquiriram maiores conhecimentos nos campos da cirurgia, assepsia, anestesia, hemoterapia e antibioticoterapia. O domínio das técnicas ampliaram as possibilidades de intervenção e a cesariana se torna nesta época como uma opção por excelência de resolução da gravidez.

A partir da institucionalização do parto e em recentes décadas, tem se buscado aprimorar as práticas para iniciar, acelerar, adequar ou monitorizar o processo fisiológico do trabalho de parto.

A tendência em transformar um evento fisiológico normal em um procedimento médico/ cirúrgico restringe o espaço ou a liberdade das mulheres em experienciar em toda a sua plenitude o nascimento de seu filho, e abre espaço para as intervenções desnecessárias.

$\mathrm{Na}$ tentativa de se resguardar o caráter fisiológico do nascimento, surgiu o conceito de Parto Humanizado, que pode ser descrito como um conjunto de condutas e procedimentos que têm por finalidade a promoção do parto e nascimento saudáveis e a prevenção da morbimortalidade materna e perinatal(2).

A busca pela humanização do parto exige, em primeiro lugar, o seu entendimento como sendo um evento da vida sexual e reprodutiva; um processo fisiológico, que requer um acompanhamento com um mínimo de intervenção, que disponha de pessoal treinado e de condições estruturais para identificação e prevenção precoce de complicações e situações de risco, permitindo atuação imediata, adequada e eficaz.

Neste processo, cada mulher tem uma dinâmica própria que deverá ser respeitada, deve ser estimulada a liberdade de direcionar o seu processo de parto, sendo-lhe permitido escolher onde, como e com quem pari(2).

O bem-estar da mulher e o nascimento de seu recém-nascido hígido dependem da confiança depositada nos profissionais que a assistem. Esses deverão, ao longo do trabalho de parto e no parto, avaliar corretamente o estado da mãe, com monitoramento de suas condições vitais, atentando para a manutenção de seu bem-estar fisíco e emocional, fornecendo-lhe apoio nos momentos de dor. A privacidade durante o trabalho de parto deverá ser respeitada, como também, a escolha do tipo de parto e do acompanhante que estará ao seu lado no momento que desejar.

Com a finalidade de atender melhor o processo do parto, a maneira como a parturiente percebe e interpreta as diferentes sensações fisicas pelas quais passa, é preciso considerá-lo como um processo psicossomático, que depende, além da própria evolução do trabalho do parto, do nivel de informação da mulher, da sua história pessoal, do contexto sócioeconômico, da sua personalidade e do simbolismo (3-5).

A gravidez na adolescência pode ser considerada um período de grande vulnerabilidade, e o parto nesta época é tido como um momento crítico, marcado por uma série de mudanças significativas e que envolvem diversos niveis de simbolização, como imaginar a máformação do filho ou a sua não resistência à dor. MALDONADO (1988) (3) considera o parto um "salto 
no escuro", um momento imprevisivel, irreversivel, desconhecido, do qual não se tem controle.

Mediante discussões e estudos realizados no meio científico sobre a importância da humanização da assistência direcionada ao binômio mãe-filho no ciclo gravídico, documentos do Ministério da Saúde, produzidos por autores nacionais e internacionais, apontam para a recuperação do papel das parteiras e para a qualificação das enfermeiras, a fim de reduzir as intervenções e os índices de cesáreas, por serem essas profissionais mais habilitadas em conduzir uma assistência natural e mais humana, já historicamente comprovada(6-8)

Ao perscrutar a literatura acerca do parto humanizado, não encontrei nenhum trabalho que sustentasse esse tipo de assistência na -visão dos sujeitos que o vivenciaram. Além disso, a literatura referente à gestação/parto na adolescência está direcionada aos problemas biopsicossoais que podem advir da maternidade precoce e aos riscos obstétricos e neonatais da gestação/parto na adolescência, enxergando o fenômeno através do olhar clínico, censurador e normatizador. Porém, há um lado obscuro, não percebido. O foco dos estudiosos é incapaz de iluminar, clarear esse lado, que se refere à subjetividade do sujeito que vivencia o fenômeno. Os sentimentos, as atitudes, os desejos, as necessidades das adolescentes ao passarem por essa experiência existencial, não são levados em consideração.

Dessa forma, na busca incessante de conhecer melhor o fenômeno, passei a enxergar o ser adolescente-parturiente por um outro prisma, deixando de lado meus pré-conceitos e concepções apriorísticas com relação à sua vivência como gestante-parturiente. Essa postura não de neutralidade, e sim de envolvimento, levou-me a perceber que é preciso deixar que as adolescentes expressem suas vivências no momento do trabalho de parto e no parto, conforme sua percepção. Assim, a partir de suas descrições, procurei compreender o que significou para elas ter passado pelo momento de pré-parto e parto, dito humanizado, entendendo que a vivência do parto não é algo que acontece desgarrado da experiência de vida da adolescente, de sua facticidade, mas ela realiza-se paralelamente a outras dimensões existenciais, conforme condição vivida por ela, ou melhor, na sua relação com o mundo e com o outro.

\section{TRAJETÓRIA METODOLÓGICA}

Como enfermeira obstetra e pesquisadora, entendo que a vivência da mulher adolescente no desenrolar do trabalho de parto e no parto seja um fenômeno obscuro, que merece ser compreendido, uma vez que se trata de uma experiência concreta, vivenciada por ela em seu mundo-vida. Por assim pensar, elegi a fenomenologia como trajetória de pesquisa, já que era uma experiência existencial, e que solicitava os pressupostos da fenomenologia para descrever, explicitar e compreender os aspectos essenciais do fenômeno. Para fundamentar a análise compreensiva/interpretativa das categorias analiticas, utilizei, além dos autores que trabalham a temática estudada, a fenomenologia existencial à luz de Maurice Merleau-Ponty.

Acreditava que desvelando a essência do fenômeno, eu estaria contribuindo para a melhoria da assistência direcionada à mulher no processo de parto.

O local escolhido para o estudo foi o Hospital Sofia Feldman, localizado na periferia do municipio de Belo Horizonte-MG. A escolha desse local deveu-se ao fato de o mesmo ter feito parte do meu cotidiano de trabalho, como enfermeira obstetra.

Antes, porém, do processo de coleta de dados, busquei atender às exigências do Conselho Nacional de Saúde e submeti o projeto de pesquisa ao Comitê de Ética da Universidade Federal de Minas Gerais, atendendo assim, à Resolução de número 196/96, que trata de pesquisas envolvendo seres humanos.

Os sujeitos da pesquisa foram as puérperas adolescentes que passaram pela experiência do trabalho de parto e do parto dito humanizado. Após apresentação sucinta da pesquisa, convidava-as para participarem. Caso aceitassem, informava-lhes sobre a necessidade de ter o seu consentimento por escrito, como também, o de seus pais ou responsável.

Para obtenção dos dados utilizei observação de campo e entrevista aberta, norteada por duas questões: "Conte para mim como foi sua experiência durante o tempo em que esteve em trabalho de parto"; e "Fale para mim como foi seu parto".

Como recurso metodológico utilizei o gravador, que permitiu-me registrar as falas na integra. As entrevistas foram trancritas em sua totalidade; assim que percebi que havia repetição de conteúdos nos relatos dos sujeitos, dei por encerrada essa etapa, com oito entrevistas.

De posse dos relatos das adolescentes e das observações de campo, realizei a análise compreensiva e interpretativa dos significados emergidos dos discursos e das observações de campo. Para isso fundamentei-me nos momentos de análise sugeridos por Martins, Bicudo (9), também, denominado análise ideográfica, o que permitiu-me construir três categorias de análise, que se constituíram na estrutura situada do fenômeno (essência): Pré-parto/ parto: o corpo sendo controlado; Pré-parto/ 
parto: misto de dor e de prazer; e Parto Humanizado: a assistência esperada e desejada.

\section{A CONSTRUÇÃO DOS RESULTADOS}

\section{Pré-parto/parto: o corpo sendo controlado}

Esta categoria possibilitou-me apreender das falas das parturientes adolescentes, que, às vezes, sentem-se cerceadas em suas reações, o que as deixa insatisfeitas com o tipo de assistência recebida: "Dá um medo, uma aflição, o pessoal tudo pedindo para ficar quieta, mas não tem jeito, a dor é muito forte, eu fiquei foi andando nas duas salas, eu não agüentei fícar deitada..." (E3).

A postura do profissional pode; muitas vezes, interferir na evolução normal do trabalho de parto. Por exemplo: quando, de uma forma um tanto ríspida, chama a atenção da parturiente, com relação a maneira como se comporta no momento das contrações uterinas, impedindo-a de expressar livremente, por meio de seu corpo, o que está vivenciando. Dessa forma, está, também, contribuindo para a medicalização do parto, ou seja, interferindo no processo fisiológico do nascimento, como retratado no relato seguinte: "Eu tava na sala agachada, eu fazia força, mas não dilatava, não acontecia nada...até que elas chamaram o médico para ajudar, ai foi ruim. Se eu soubesse que fosse para chegar lá e eu ganhar, tudo bem, mas agora, ficar lá esperando e o médico ficar em cima de você ajudando a sair, é ruim...ai me levaram pra sala da mesa deitada, me cortaram e puxaram o menino, porque já tava ficando sem ar lá dentro. Foi ruim e as pessoas nem entende..." (E3).

A maneira como as parturientes descrevem seu parto, mostra uma relação de distanciamento entre o profissional e elas. Não há interação no sentido do afeto, da aproximação, do cuidar verdadeiro. Nessa situação, o corpo é visto e manipulado como um objeto, que à semelhança de uma máquina recebe tratamento semelhante. Não importam os sentimentos expressados pela parturiente, naquele momento a eficiência,a resolutividade falam mais alto. A cliente fica à mercê do profissional de saúde, submetendo-se às normas e rotinas impostas pela instituição. O profissional não entende que este é um momento especial, singular para ela, e que gostaria de lembrar dele com carinho, alegria e satisfação de ter podido dar à luz.

Apreendo das falas das adolescentes que, em alguns momentos, sentem-se sozinhas em sua facticidade, o que as leva a não gostarem da assistência que lhes é prestada e que gostariam de receber ajuda no momento da dor. Talvez por ser a dor um acontecimento natural e esperado no processo do parto, o profissional de saúde pede com insistência controle e tranqüilidade por parte da adolescente, esquecendo-se com isso que cada individuo tem um certo limiar de tolerência para a dor, o que, por sua vez, pode ser potencializado por questões emocionais, psicológicas, culturais, etc. Os fragmentos das falas retratam essa situação: "O pessoal não ajuda, a gente sente dor e ninguém ajuda, manda a gente ficar quieta, não gritá. Mas, quem tá sentindo a dor é nóis. Eu não gostei daqui não" (E5); "Ah, foi horroroso, muito horroroso. Ah, eu não podia gritar..." (E3). De acordo com Merleau-Ponty(10), o corpo é iminentemente um espaço expressivo. Ele é a origem de todos outros espaços expressivos, ele é o próprio movimento de expressão, aquilo que projeta as significações no exterior dando-lhes um lugar, aquilo que faz com que elas comecem a existir como coisas, sob nossas mãos, sob nossos olhos.

É, pois, o corpo da adolescente parturiente que percebe o mundo da sala de parto, a forma como as pessoas se aproximam dela e tocam seu corpo; é a partir de sua percepção, na intencionalidade corporal, que vai atribuir um sentido àquele momento, sentido este revestido de medo, angústia e exacerbação da dor.

O toque vaginal teve destaque nas falas das parturientes como sendo um dos procedimentos mais incômodos e dolorosos. As adolescentes entrevistadas não foram capazes de entender a sua necessidade. Parece que para elas trata-se de um procedimento sem uma finalidade bem definida, mas sim um procedimento invasor, realizado de qualquer jeito: "E as médicas vinham fazer exame para ver como é que eu estava de dilatação..." (E6); "Eu só não gostei quando enfiaram o dedo..." (E2); "O toque é ruim, machuca, parece que eles não estão nem ai, se não fosse o toque e as dores, depois, eu não tinha nada pra reclamar" (E3).

A situação de parto faz com que a exposição e a intrusão alheia no corpo sejam fatos normais, corriqueiros, e aceitáveis, portanto, o profissional arvora-se o direito de manipular a parturiente quantas vezes forem necessárias, tudo em prol de uma boa causa. Diante dele posta-se um ser assexuado, sem sentimentos, subserviente e alheio às condições circundantes. Parecem insensiveis se a adolescente fecha os olhos de vergonha ou de dor, o mais importante é que tudo encaminhe para o normal. Assim, eu me questiono: está correto o excesso de toques vaginais, quando a instituição tem por filosofia o parto humanizado? Não seria mais adequado permitir que a adolescente extravase sentimentos, e 
participe ativamente do processo de nascimento do filho?

Em relação ao uso da cadeira de cócoras, penso que o desconhecimento de como se posicionar nela, como, também, seus beneficios para ajudar na aceleração do parto, fizeram com que muitas das parturientes entrevistadas não tivessem gostado dela, achassem horrivel a posição, mas se submeteram à situação: 'Ai meu Deus, foi horrivel! Eu entrei aquilo ali tipo uma cadeira. Ai veio as contrações ela mandou eu forçar para baixo $e$ nada do neném sair, e fiquei mais ou menos tentando fazer naquele ferro, lá forçando para baixo, mais ou menos 20 minutos, cada vez que a contração vinha, e ela estava vindo mais rápida. Chegou uma hora que eu já não tinha força nenhuma, ai eu sentei na cadeira e eles teve que dar anestesia e cortar" (E6).

Eu acredito na humanização do parto e, dentro de seus preceitos, nos beneficios do parto de cócoras. Essa forma de parir, entretanto, é desconhecida pela maioria da população urbana e, como tudo o que é diferente e que será experimentado pela primeira vez, causa um certo medo e desconforto. No entanto, o contrário ocorreu com aquelas que tiveram a oportunidade de conhecer a sala antes do parto e obter informações sobre seus efeitos. Elogiaram, afirmando que é uma forma de fazer o neném nascer mais rápido, e de sentir menos dor: "...Achei ela boa pra ajudar

o neném a descer..." (E7); "...Achei a sala boa, melhor do neném sair mais rápido, e a gente sente menos dor. Sentada fica melhor" (E8).

O corpo da parturiente adolescente, como nó de significações vivas, enquanto veículo motor no mundo, percebe a sua facticidade: ser adolescente e conviver com o parto, atribuindo a esse momento existencial um sentido conforme sua visão de mundo. Impedir que reaja, tocá-la em demasia, sujeitá-la ao parto de cócoras são situações impostas pela instituição e, às vezes, não aceitas pela parturiente, porque se sente inautência em seu ser. É preciso, portanto, aguçarmos nossos sentidos, sermos mais sensiveis às reações das adolescentes para percebermos que ali existe um corpo que transcende o biológico. É mais que um corpo fisico, composto de ossos, órgãos justapostos, músculos, sangue, linfa, tecidos...é

o corpo encarnado, vivo, pulsante na fala de MerleauPonty. É o corpo que exala, que se mostra, que tem sentimentos, que é capaz de chorar, de sorrir, de sofrer, de ser feliz, de dizer que é existente, que merece respeito por parte dos profissionais de saúde.

\section{Pré-parto/parto: misto de dor e de prazer}

Apreendo dos relatos que o pré-parto e parto são momentos demarcados por muita dor, muito sofrimento, e pelo alivio, pela alegria e pelo prazer na expulsão do bebê. Assim, dor e prazer mesclam-se, misturam-se, constituindo o amálgama que reveste esse momento existencial.

A dor mostrou sua presença constante nas falas das adolescentes. Ela se cristaliza em seus corpos, impregna seu existir, fazendo com que a adolescente sinta medo da morte, aflição, insegurança: "...Assim, eu acho que o que atrapalha mesmo são as contrações... a dor maior é a da contração..." (El); "..é uma dor insuportável que você pensa que nunca vai passar, dói muito..." (E2); "...foi muito dificil porque eu nunca imaginava que eu fosse passar por tanta dificuldade...eu pensava que não ia agüentar. Tava dificil demais" (E7).

A dor do trabalho de parto, para a maioria das adolescentes que vivenciaram tal experiência, é algo bem vivo, presente em suas falas, no entanto, cada uma vivenciou essa dor de uma forma bastante particular, expressando-se através de seu corpo o que acontecia com ela. Cheguei a perceber que as adolescentes, às vezes, precisavam gritar, não ficar estáticas, submeter-se ao controle, ter alguém ao lado, ingressar no mais íntimo do seu ser, permitir-se mais, para conseguir passar por esse "vulcão" de sensações.

Vencidas as dores das contrações uterinas, a adolescente se deleita com o nascimento do filho, e a paz é restabelecida. Num verdadeiro encontro, mãefilho, doam-se, tocam-se, brindando assim esse momento sublime da existência humana: "...foi muito bom...eu tô feliz" (E4).

As adolescentes mostraram, em seus relatos, que o parto pode transformar-se em um momento de prazer, de satisfação, de plenitude, de alivio, graças ao nascimento do filho: "...depois só de você está segurando o neném, você se sente acalentada, a dor passa..." (E2); "...é bom depois que nasce..." (E6); "...o alivio é quando sai, quando sai também acabou..." (E3); "..ffoi muito bom...eu tô feliz" (E4).

O enlevo materno faz desaparecer toda a turbulência vivida nos instantes que precedem a expulsão do bebê e resplandece à luz do aconchego, da carícia, da doação, da solicitude no cuidar de um ser esperado e amado pela adolescente.

O vínculo mãe-bebê depende, também, da capacidade do bebê em identificar sua mãe. A importância de favorecer o contato olho-a-olho do bebê com sua mãe, logo após o nascimento, para que se estabeleça o vínculo, foi constatada em todas as observações realizadas na sala de parto. O corpo do bebê junto ao corpo da mãe parecia uma coisa só, unívocos. Eles pareciam agir sincronicamente, ou melhor, respiravam numa cadência harmônica; olharam-se, conheceram-se, pelo toque e pelo cheiro, entregavam-se passivamente um ao outro, e toda turbulência vivenciada no pré-parto e no parto era 
dissipada e suplantada pelo prazer de estarem ali juntos. Entre eles selava-se a relação ser-com-o-outro-no-mundo, por meio do encontro intersubjetivo. Klaus e Kennell(11) afirmam que há um "harmonioso nexo nas reações de ambos, semelhante a uma dança sincronizada entre mãe e filho".

Tão logo o nascimento tenha ocorrido, evidenciei um semblante de alívio em todas as parturientes estudadas, o que foi ratificado nas falas a seguir: "...o alivio é quando sai, quando sai também acabou" (E3); "..eu acabei conseguindo...foi muto bom..." (E4); "...Quando nasceu é que foi um alivio" (E5).

Apreendo das falas das adolescentes que o nascimento representa o grande divisor de águas, ele separa um periodo sofrido, doloroso, o do trabalho de parto, de um outro tranqüilo e prazeroso, o da expulsão do bebê. É como se naquele momento sublime finalizasse mais uma etapa da vida da mulher, e se anunciasse uma outra fase, na qual a vinda da criança ratificasse o papel de mulher, de mãe, de cuidadora. Para Largura (12), um parto confirma ou não na mulher a sua capacidade de colocar uma criança no mundo. É um rito que marca profundamente seu inconsciente. O primeiro parto é um rito de passagem para uma nova etapa de sua vida de mulher.

No Hospital Sofia Feldman, a sala de parto tende a ser um ambiente próximo ao familiar, por promover o encontro da adolescente com o companheiro, ou com outra pessoa de seu desejo, e desses com o bebê. Um ambiente natalino se faz presente quando o bebê nasce e é apresentado à família, como pude observar durante o parto de uma das adolescentes, onde a presença do companheiro proporcionou-lhe tranqüilidade, fazendo com que parasse de gritar e ajudasse no puxo, o que auxiliou no nascimento do filho. Após este momento, o casal se abraça e se beija, afagando o bebê.

Neste ritual, em que a presença paterna é solicitada para selar com gesto de amor e carinho a vinda do filho ao mundo, percebo o quanto este momento é importante, principalmente, para a adolescente. Ele se materializa no alívio, na cessação das dores, no descanso, na paz e na satisfação de ter podido dar à luz. Além do mais, a participação e o envolvimento do companheiro ou de outro acompanhante, no momento do parto, aliados à satisfação de todos poderem compartilhar desse momento, dá mostras suficientes da necessidade de se manter o caráter humanizado do parto.

\section{Parto Humanizado: a assistência esperada e desejada}

Esta categoria mostra, pelos discursos dos sujeitos e pelas observações de campo, que é possivel estabelecer uma relação autêntica com o outro, quando se tem por objetivo o parto humanizado.
Neste estudo, observei que as adolescentes são encorajadas a ser ativas no trabalho de parto, a escolher a sua companhia, a utilizar novas formas de relaxamento, a escolher dentro da posição vertical, aquela que lhes proporcione um certo bem-estar, ou, quando no leito, a ficar em decúbito lateral esquerdo. Além disso, as parturientes têm o suporte físico e emocional, oferecidos pelos profissionais da psicologia, pela equipe de enfermagem e pelos demais profissionais que venham a entrar em contato com elas.

Uma forma de favorecer um ambiente mais tranqüilo à parturiente e que acontece na instituição de estudo é a diminuição do número de pessoas estranhas no pré-parto, colocando ao seu lado uma pessoa conhecida, que seja do desejo dela, com quem ela se sinta segura.

Durante a observação, na sala de parto, pude constatar o quanto foi importante para uma das adolescentes a presença de sua mãe e a de seu companheiro, proporcionando-lhe segurança, estando ao seu lado: segurando-lhe as mãos, incentivando-a no puxo. Ela parecia sentir-se mais capaz de ajudar o filho a nascer.

No Hospital Sofia Feldman, as atitudes de apoio e de respeito à privacidade são de responsabilidade de todos os profissionais que entram em contato com a parturiente. No entanto, como a enfermeira fica mais envolvida em procedimentos técnicos, a doula, o psicólogo, os voluntários de psicologia e a assistente social ficavam responsáveis pelo apoio emocional à adolescente.

A doula é uma prestadora de serviços que recebeu treinamento básico sobre parto, estando familiarizada com uma ampla variedade de procedimentos de assistência. Tem como atividades, fornecer apoio emocional por meio de elogios, reafirmações, contato físico, como friccionar o dorso da parturiente, segurar suas mãos, como atendê-la em suas necessidades básicas; enfim, dar-lhe explicações sobre o que está acontecendo durante o trabalho de parto; sendo assim, uma presença amiga constante. E um elemento importante no elo entre a parturiente-família-equipe de assistência.

A solicitude das doulas perpassou nos discursos das adolescentes. Elas descreveram essa mulher como alguém que as ajudou na superação da dor do trabalho de parto. Como pude evidenciar no discurso a seguir: "...porque todo mundo me ajudava...a enfermeira e aquela senhora enfermeira. Ela ia lá, buscava água pra mim, ela fazia massagem pra parar de doer, ela ficava perto de mim, pra tudo que eu quisesse ela me ajudava. Pra mim foi legal, porque eu não tava agüentando e elas me ajudaram..." (E7).

Uma forma não farmacológica de intervir na dor 
vivenciada pela parturiente se dá pela maneira como o profissional ou a pessoa que a está assistindo a toca. A massagem proporcionou um grande alivio às parturientes, como evidenciei em suas falas: "...E vinha a $D^{\circ} E$, e fazia massagem em mim, porque eu tava sentindo muita dor...Em termo da dor foi horrivel e pelo menos as doula e as doutoras foram muito paciente e atenciosa" (E6).

Percebo nas falas das adolescentes a massagem não apenas como um ato mecânico, físico, das mãos, mas como a concretização de um cuidar mais abrangente. Tocar representa naquele momento estarcom-outro. A mão como extensão de um corpo encarnado, aproxima duas pessoas, no sentido do afeto, do carinho, do desvelo, da solicitude, da segurança, da presença no mundo, no encontro. É o despojar de um ser que se coloca aberto, solícito para o outro. "A mão que toca, cura porque leva caricia, devolve confiança, oferece acolhida e manifesta cuidado. A mão faz nascer a essência humana naqueles que são tocados" (13). Desde a admissão até a sala de parto constatei, durante as observações, que apesar da sobrecarga de trabalho, todas as enfermeiras antes de iniciarem qualquer procedimento com a parturiente, paravam para explicar-lhe o que iriam fazer e porque isso era necessário; respeitavam a privacidade da adolescente e, muitas vezes, seus desejos eram atendidos. Após cada procedimento explicavam-lhe o que haviam encontrado.

Em julho de 1999, o Hospital Sofia Feldman recebeu o Prêmio Galba de Araújo, oferecido pelo Ministério da Saúde às unidades de saúde que se sobressairam no atendimento obstétrico e neonatal, sobretudo, nos aspectos da humanização da assistência, estímulo ao parto normal e aleitamento materno, incentivando as maternidades a acolherem com respeito e dignidade as mulheres brasileiras, a fim de que sejam assistidas com presteza, solidariedade e gentileza que a ocasião exige. Identifiquei nos relatos abaixo algumas características da assistência humanizada, que contribuíram para que o hospital recebesse o referido Prêmio: "...Eu gostei tanto da assistência porque elas me trataram tão bem... não posso reclamar de nada, absolutamente nada, principalmente das enfermeiras, até esse instante elas estão me tratando hiper bem, toda hora chega uma $e$ pergunta como é que eu tô, se preocupam comigo. Todo mundo fez o possivel para me ajudar mesmo...elas me ajudaram bastante" (E2); "...a médica era legal, e as duas enfermeiras também" (E3); "Ah, pra mim foi muito bom, porque as pessoas me trataram bem...todas as pessoas me trataram hiper bem...Eu tive o parto na sala de cócoras... foi muto dificil, mas as pessoas me ajudaram, me deram a maior força, a enfermeira e as outras pessoas que estavam lá me deram a maior força e eu tô feliz "(E4); "...Em termo da dor foi horrivel $e$ pelo menos as doula e as doutoras foram muto paciente e atenciosa"(E6).

Para a Organização Mundial de Saúde (14), a qualidade do acolhimento à mulher que procura uma assistência institucional pode determinar o nível de confiança que ela e sua família sentem que podem ter em relação aos seus prestadores de serviço.

Após ouvir e observar as parturientes adolescentes no processo do parto, pude depreender o desfecho final desse momento singular, impar na vida delas, no qual selava todo o enlevo vivido, e se ratificava a humanização da assistência ao parto: a relação autêntica de um ser com um outro ser.

\section{CONSIDERAÇÕES FINAIS}

Este trabalho possibilitou-me compreender que a adolescente, na vivência do parto, não é apenas um corpo físico, biológico, sujeito às leis de causa e efeito, mas um corpo que tem sentimentos, que mostra por gestos, gritos, choro, silêncio, como vivencia esse momento.

Esta investigação levou-me a desvelar uma das facetas do fenômeno estudado. Consegui compreender o que significa para a adolescente vivenciar o pré-parto e o parto dito humanizado. Percebi que, apesar de ser um momento impar, singular para cada adolescente, apresentaram reações, comportamentos semelhantes, já que o parto é um evento da vida cercado, culturalmente, por muito medo, principalmente das dores das contrações.

Aprendi que, como profissional de saúde, é necessário interagir com o outro com mais respeito e dignidade, entendendo que são experiências adversas, visões de mundo diferentes, e como tal exigem de mim uma postura mais humana, livre de preconceitos. É preciso que eu direcione o meu olhar para a compreensão do sujeito, tentando assim estabelecer com ele uma relação de empatia, de ajuda, o que pode amenizar a situação vivenciada por ele.

Esta compreensão só foi possivel a partir do momento que elegi a fenomenologia como trajetória metodológica. Ela permitiu, inicialmente, desligar-me do meu ver profissional rotineiro e perceber o fenômeno da forma como ele se mostrava. Além de possibilitar-me chegar à essência do fenômeno, a fenomenologia mostrou-me uma maneira diferente de ver o mundo, entendendo que lido com seres humanos, que não devo tecer julgamentos prévios acerca de situações do meu mundo profissional. É preciso que, primeiramente, compreenda o indivíduo que vive a experiência, só assim poderia estar ajudando-o, e 
amenizando, quem sabe, o seu sofrimento. A compreensão permite entender o outro em sua facticidade, existindo no mundo e estabelecendo com ele relação de reciprocidade.

Depreendi que algumas técnicas, como o toque vaginal e o posicionamento na cadeira de cócoras, quando não explicadas previamente, constituem uma agressão para as adolescentes.

Outras situações apontaram, que apesar de toda turbulência vivenciada com as contrações, as adolescentes experimentam sentimentos de alivio e de prazer quando o bebê nasce e ao tê-lo em seus braços. A presença do companheiro, ou de alguém que possa aliviar seus medos e suas tensões, contribui, também, para que o parto seja um momento de deleite e de prazer.

O papel da equipe de saúde é extremamente importante, quando se tem por meta a humanização do parto. Apesar da instituição estudada ter por filosofia a assistência humanizada ao parto, em alguns momentos evidenciei o cumprimento de normas e rotinas em demasia, o que fez as adolescentes sentirem-se agredidas e submissas a tais procedimentos. Neste sentido, a instituição deve buscar formas que possibilitem o real cumprimento dos pressupostos de uma assistência mais humanizada ao parto.

\section{REFERÊNCIAS BIBLIOGRÁFICAS}

(1) Hospital Sofia Feldman. Regimento do serviço de enfermagem. 1995. (Mimeografado)

(2) Secretaria de Saúde do Estado de Pernambuco. Parto humanizado. Recife: S.S.;1997. (Cadernos de Textos- Série Saúde da Mulher e do Adolescente).

(3) Maldonado MTP. Psicologia da gravidez, parto e puerpério. 9ed. Petrópolis: Vozes; 1988.

(4) Simões SMF, Souza IEO. Vivência de parturientes: observação de enfermagem. Rev Bras Enferm 1997; 50(4):507-16.

(5) Pamplona V. Mulher, parto e psicodrama. São Paulo: Agora; 1990.

(6) Ministério da Saúde. Coordenação de Saúde da Mulher. Promoção ao parto normal. Brasília: MS; 1993.

(7) Secretaria de Saúde do Estado do Ceará. Manual do parto humanizado. Fortaleza. 2000. (Projeto Luz da JICA. Agência de Cooperação Internacional do Japão em parceria com o Governo do Estado do Ceará).

(8) Zugaib MA. A via de parto. Rev Ginecol Obstetr 1990; $1: 52-8$.

(9) Martins J, Bicudo MAV. A pesquisa qualitativa em psicologia: fundamentos e recursos básicos. led. São Paulo: Moraes, 1989.

(10) Merleau-Ponty M. Fenomenologia da percepção. São Paulo: Martins Fontes; 1999.

(1 1) Klaus MH, Kennell JH. La relación madre hijo: impacto de la separación o pérdida prematura en el desarrollo de la família. Buenos Aires: Panamericana; 1978.

(12) Largura M. A assistência ao parto no Brasil psicológicos: aspectos espirituais, biológicos e sociais; uma análise critica por um parto mais humano e solidário. 2.ed.São Paulo: [s.n]; 2000.

(13) Boff L. Saber Cuidar: ética do humano, compaixão pela terra. 5.ed. Petrópolis: Vozes; 2000.

(14) Organização Mundial de Saúde Assistência ao parto normal: um guia prático. Genebra: OMS/SRF/MSM; 1996.

\title{
Artigo recebido em 10/07/01
}

\author{
Artigo aprovado em 03/09/02
}

